\title{
3 Constructing an inclusive vision of sustainable transition to decentralised energy
}

\author{
Local practices, knowledge, values and \\ narratives in the case of community-managed \\ grids in rural India
}

Anna Melnyk and Abhigyan Singh ${ }^{1}$

\section{Introduction}

Deep within a tropical forest in central India, more than 100 small-scale (1-8kW) decentralised solar mini-grids have been structured by the provincial government. These stand-alone grids are instituted as part of the government's drive for completing rural electrification of the region. At the outset, there is hardly anything technologically exciting about these grids. The grid does not incorporate any intelligence or high-tech innovations and is entirely constituted by mundane technologies, such as solar panels, lead-acid battery-banks and electrical cables. However, it is remarkable that the villagers entirely manage the day-to-day functioning of these grids. The villagers have been able to manage these grids for over a decade communally. This situation raises an intriguing question, i.e. are insights from these sites relevant for a vision of sustainable energy transition (SET) in the global North?

As a product of the global North, a vision of SET that informs policies and infrastructural developments has a strong reliance on high-tech energy innovations and market design. This vision is informed by the universal, singular and homogenous views of SET that are often guided by rational values of efficiency, optimisation and maximisation. At the same time, this vision of SET holds a limiting account of diverse energy-related practices and associated values that are endemic to local communities. In this chapter, we hint at alternative possibilities for SET to decentralised energy by presenting insights from an ethnographic study on decentralised solar mini-grids in rural India. Furthermore, we utilise the case to learn about local knowledge, values, practices and narratives with energy technologies. Overall, in this chapter, we do not aim to provide a solution, but rather take a step towards a long process of construction of a "big picture" of the sustainable transition to decentralised energy.

We start this chapter by introducing a vision of the global North on SET reflected in both academic literature and a key policy document in the European 
Union - the EU directive. Then, after providing relevant background information on the community-managed solar mini-grids in rural India, we extract empirical insights about local narratives, knowledge, values and practices. Finally, to conclude, we combine these insights to reflect upon an inclusive view of the sustainable transition to decentralised energy.

\section{The global North's visions of sustainable energy transition (SET)}

Since 1970, contemporary societies have been facing a significant environmental crisis that has created new societal, institutional and design challenges (Singer 2002). The urgent demand in shifting from non-renewable and extractive options to sustainable ones is motivated by concerns about climate change and the depletion of fossil fuels (Kern \& Smith 2008; Coenen et al. 2012). The value of sustainability has become a cynosure and is now commonly discussed in the context of the energy transition (Cuppen et al. 2016; Van de Poel 2017; Mok \& Hyysalo 2018). It is a crucial concept guiding current low-carbon energy transitions for the last few decades (Smith et al. 2010; Verbong \& Geels 2007; Rae \& Bradley 2012). The contemporary conceptualisation of sustainability in the global North is often linked to "sustainable development". It refers to Brundtland's definition: "[the] development that meets the needs of the present without compromising the ability of future generations to meet their own needs" (WCED 1987, p. 43). Such a link between "sustainability" and "sustainable development" commits to the essentiality of the idea of economic growth (Spangenberg 2004). Technological innovation plays a key role here as they support the simultaneous achievement of both aims - sustainable transition and economic growth.

Engineers and policy-makers in the global North are applying various methods to embed the value of sustainability in technological and institutional designs to facilitate SET (Mok \& Hyysalo 2018; Taebi \& Kloosterman 2015; Van de Poel 2017). The introduction of new energy technologies that embed sustainability has created the opportunity for the empowerment of local communities and, subsequently, the societal interest in the decentralisation of energy production, generation and supply increase (Rae \& Bradley 2012; Koirala et al. 2016; Rogers et al. 2008; Hoppe et al. 2015). Besides a genuine societal interest in decentralisation, a SET through community engagement is also a climate change mitigation strategy (Koirala et al. 2016; Rogers et al. 2008; Becker \& Kunze 2014; Verkade \& Höffken 2019). In the European Union, local SET aligns with the agenda for institutional change set up by the Paris Climate Agreement in 2015.

Indeed, numerous new environmental policies aim to foster SET by involving citizens and local communities in the generation of renewable energy (Koistinen et al. 2018; Heldeweg 2017). When producing and delivering an excess of energy to the grid, the consumers are being transformed into prosumers (Koirala et al. 2016). The Netherlands, the UK and Germany are leaders in promoting and implementing the new agenda for the SET (Becker \& Kunze 2014; Magnusson \& Palm 2019; Hoppe et al. 2015). The possibility of fulfilling such SET is heavily 
interdependent with advanced technologies as it is closely linked with the production of new technologies and economic growth. Innovative technologies, such as blockchain, are often given priority in energy decentralisation as they are considered a secure and privacy-enhancing method of energy transactions among local communities (Aitzhan \& Svetinovic 2018). Using the possibilities provided by encryption algorithms, smart contracts (i.e. a type of contract for blockchainbased infrastructures) and distributed data, self-sufficient energy systems can be created (Wu \& Tran 2018). These innovative technologies do not just enable local communities to meet the value of sustainability but also address other important values like energy security, reliability and privacy (Aitzhan \& Svetinovic 2018).

A reference to advanced technological practices in the context of SET can be found in numerous policy documents. In the EU directive 2018/2001 of the European Parliament and of the council of 11 December 2018 on promoting the use of energy from renewable sources, a crucial policy document, this implicit bias is traceable. This directive contains SET goals that all European Union countries must aim for (Union 2018). Although it is up to each country to decide how to achieve these goals, the directive is still consolidated and delivered across a precise vision of SET. Technological advancements are particularly emphasised and are at the core of the SET vision expressed in the directive (Union 2018). For example:

(76) The Energy Union strategy also recognized the role of the citizen in the energy transition, where citizens take ownership of the energy transition, benefit from new technologies to reduce their bills, and participate actively in the market

(emphasis added, Union 2018, p. 93)

(86) With regard to Intelligent Transport, it is important to increase the development and deployment of electric mobility for roads, as well as to accelerate the integration of advanced technologies into innovative rail

(emphasis added, Union 2018, p. 95)

(5) Member States shall ensure that guidance is made available to all relevant actors, in particular to planners and architects so that they are able properly to consider the optimal combination of energy from renewable sources, of highefficiency technologies, and of district heating and cooling when planning, designing, building and renovating industrial, commercial or residential areas

(emphasis added, Union 2018, Article 18, p. 117)

(1) The Commission is empowered to adopt delegated acts in accordance with Article 35 to amend the list of feedstock set out in Parts A and B of Annex IX by adding, but not removing, feedstock. Feedstock that can be processed only with advanced technologies shall be added to Part A of Annex IX. Feedstock that can be processed into biofuels, or biogas for transport, with mature technologies shall be added to Part B of Annex IX. Such delegated acts shall be 
based on an analysis of the potential of the raw material as feedstock for the production of biofuels and biogas for transport.

(emphasis added, Union 2018, Article 28, p. 128)

The EU directive rests on pushing high-tech technological advancement to achieve economic growth without critical reflection upon alternative ways. The directive holds a strong association with hi-tech energy innovations and market designs - a vision of SET from the global North's perspective. In the SET literature, there is a heavy focus on market mechanisms that hold a techno-optimistic view of technologies' role (Bellekom et al. 2016; Parag \& Sovacool 2016; CamarinhaMatos 2016). Such a vision of the SET brings the implicit bias of technological advancements being taken for granted with accompanying ideas and beliefs in the market's ideals and its design that leads to economic growth. This universal, singular and homogenous view of SET is guided by rational values of efficiency, optimisation and maximisation (see examples: Smith et al. 2010; Ilic et al. 2012; Camarinha-Matos 2016; Saad et al. 2016; Kuzemko et al. 2017; King \& Van Den Bergh 2018). This view frames the way communities' needs, values and visions are understood without taking into account the plurality of local narratives and knowledge. This may lead to strained relations between the local perceptions of desirable economic growth and the vision of SET imposed by the EU directive.

Importantly, we do not try to claim here that economic growth is a particularly negative phenomenon. Rather the opposite, we agree that economic growth in principle aims at empowerment of local communities. However, by imposing the economic growth framework, existing social practices, local knowledge, needs and diverse values of communities might be neglected (Friedman 2006). These aspects are especially crucial for the empowerment of impoverished communities in the EU that are living outside of the technologically advanced world. These communities might have alternative low-technological solutions and local creative strategies for adaptation. Hence, we suggest that there is a need to explore local practices, knowledge, values and narratives about alternative socio-technical arrangements around decentralised energy that could enrich the dominant vision of SET in the global North policies.

To develop an inclusive and encompassing picture of SET, additional empirically grounded discussions are required. To enrich SET visions in the global North, we propose to expand the account of SET by learning from diverse energyrelated practices and associated values that are endemic to the global South. In the following couple of sections, we present a case study and draw several lessons about the alternative socio-technical arrangements around decentralised energy.

\section{Background and context of the empirical case}

In this section, we present empirical observations from an ethnographic research project on community-managed solar mini-grids in rural India. The ethnography was conducted as part of the doctoral research of one of the authors of this chapter (Singh 2019). The main objective of the ethnographic study was to understand 
the local energy-related practices of the villagers, especially when the villagers themselves manage the local decentralised grid. The field-sites were four off-grid villages where each of the villages had a stand-alone solar mini-grid of $3 \mathrm{~kW}(48 \mathrm{~V}$ DC) capacity. These villages are located in Chhattisgarh, a federal state located in central India. These four villages fall within the state's natural reserve, and hence they are officially referred to as "forest villages". See Figures 3.1 and 3.2. These decentralised grids were installed by Chhattisgarh State Renewable Energy Development Agency (CREDA), which is constituted by the Department of Energy of the Government of Chhattisgarh. Each of these villages was inhabited by 35-38 families. The field-visits, as part of the study, were conducted in 2014 and again in 2016. The study included interviews and discussion with various CREDA officials.

CREDA is mandated by the Government of Chhattisgarh to "electrify" remote villages, such as those located within the forest reserve, that cannot be connected to the centralised electricity grid. For such locations, CREDA utilises small-scale off-grid solutions, such as solar mini-grids. The government funds these off-grid

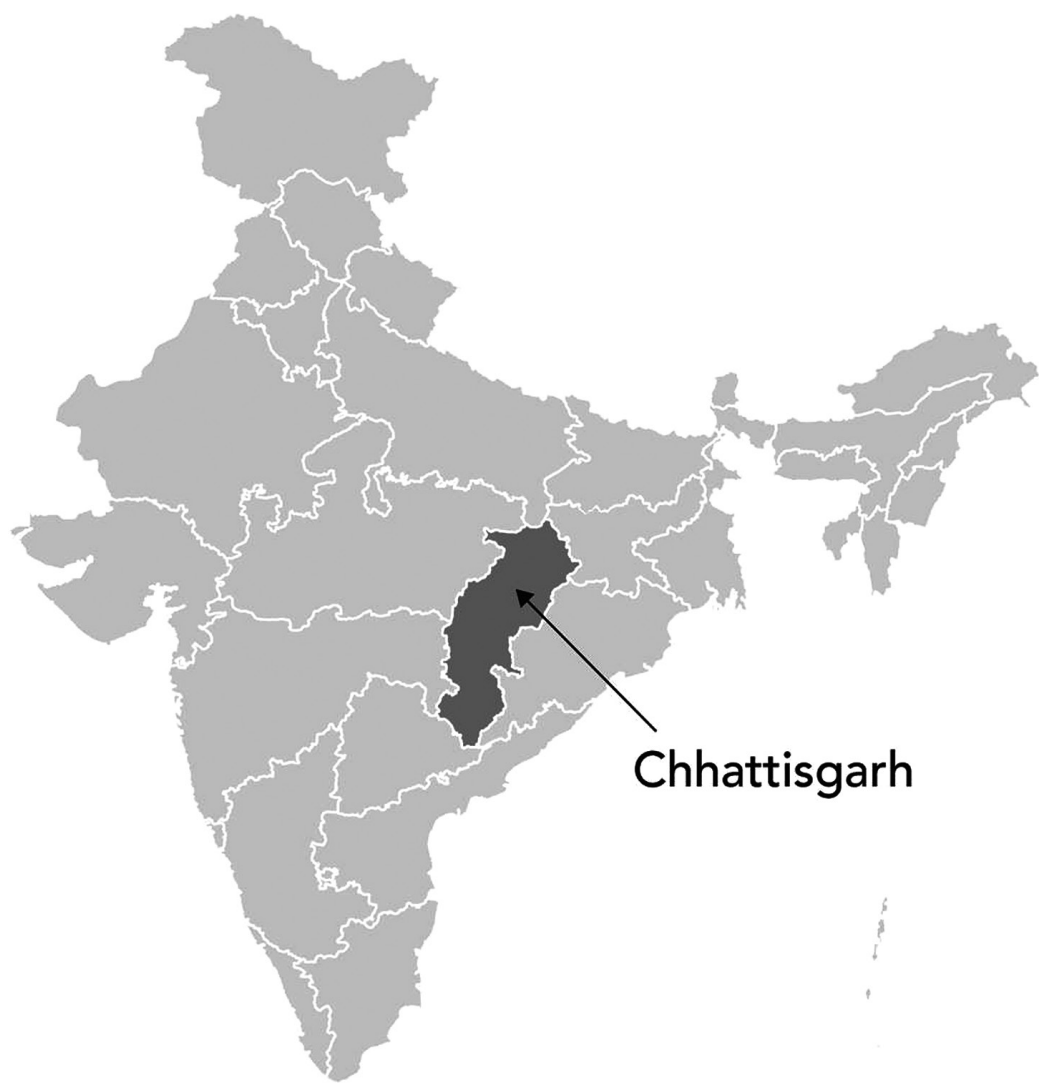

Figure 3.1 Map of India with the location of Chhattisgarh highlighted. 

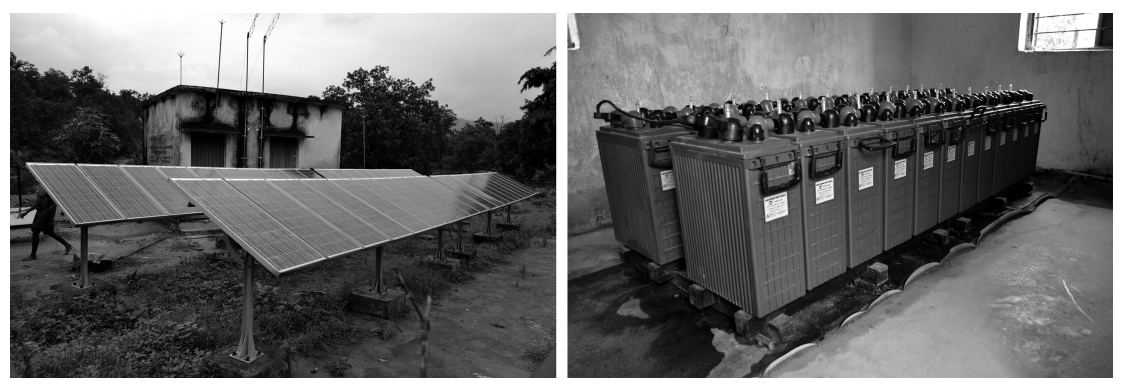

Figure 3.2 Photographs of a mini-grid at the field-site. Notice the solar panels on the ground and a battery-bank inside a control-room.

installations to achieve its ambition of complete electrification of the state of Chhattisgarh. It is worthwhile to note that the Chhattisgarh government's rural "electrification" drive is primarily focused on clean lighting provision. Therefore, the mini-grids installed by CREDA are only for lighting provision and are not aimed at supporting villagers in any local economic activity, such as electric irrigation pumps for agriculture.

CREDA considers $1 \mathrm{~kW}$ capacity to be sufficient for lighting provision for 15 families and targets that each family in a village has access to two $11 \mathrm{~W}$ compact fluorescent lamp (CFL) bulbs that should glow for seven to ten hours per day. Apart from these household-level lighting provisions, CREDA's mini-grids, which are locally referred to as power-plants, are also used for powering a few (three to five) streetlights in a village. Each of the mini-grids includes a batterybank with a capacity to store electricity to power the household-level lights and streetlights for three days without receiving any charging from the sun. The battery-banks, along with energy meters and grid-controlling switches and panels, are safely placed inside a "control-room", a physical room constructed by CREDA at each of the sites. The solar panels are either placed on the roof of the "control-room" or the ground right next to it. A "power distribution network" (PDN) consisting of electrical cables mounted and poles connect the control-room to the houses within a village.

As per CREDA's working policy, a village-level energy committee (Urja Samiti) is installed for every mini-grid. Usually, the local energy committee consists of five volunteers in the roles of grid operator, secretary and members. CREDA officials state that a local energy committee is established for ensuring daily operation of a grid and for reporting the needs for repair and maintenance. Every energy committee includes a grid operator, who is a local volunteer and is nominated by the committee. CREDA seeks a grid operator who is enthusiastic and willing to learn basic operations of a mini-grid. CREDA provides basic operational training to a grid operator. A grid operator is mainly responsible for daily operations, such as turning the grid "on or off", regular cleaning of solar panels and safety of the components of the grid. At the time of the field-visit, these grids 
have already been functioning for over eight years. CREDA officials attribute the significant role of the local energy committee and the villagers in the daily management of the grid.

\section{Decentralisation of energy grids: local practices, knowledge, values, and narratives}

\section{Local practices of improvisation, redistribution, and adaptation}

This ethnographic field-research revealed a wide range of local social practices that enabled the decentralisation of the mini-grids. This nexus of practices comprises practices of improvisation, redistribution of energy and adaptation of minigrids to fit with the dynamics of the social, cultural and economic life of the villagers. CREDA installed these decentralised grids for the primary and sole purpose of lighting provision to the remote villages. However, the villagers reported the installed connections to be limiting and "rigid". They often spoke of their needs for the energy from the grid to be organised differently for the requirements of local contexts, such as religious festivals, marriage, childbirth and illness. For instance, during a marriage ceremony in a local household, energy is required for powering devices, such as music systems, loudspeakers, and colourful lights and also these devices are desired to work beyond the $11 \mathrm{pm}$ limit set by the automatic timer of the grid. In such situations, the villagers creatively redistribute the flow of electricity by reorganising and bypassing components of the grid, such as an automatic timer and load-limiter (see Figure 3.3). Many instances of these practices are visible in these villages; for instance, villagers often tap into the PDN's cables to connect energy-consuming devices such as television sets, CD players,

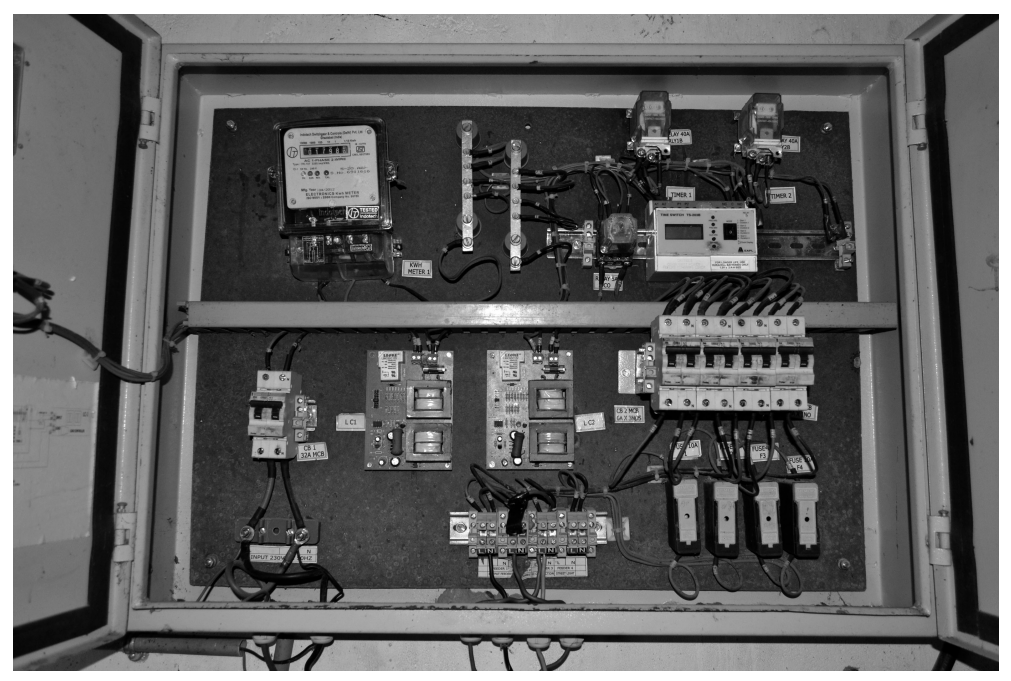

Figure 3.3 Automatic timer and load-limiter. 


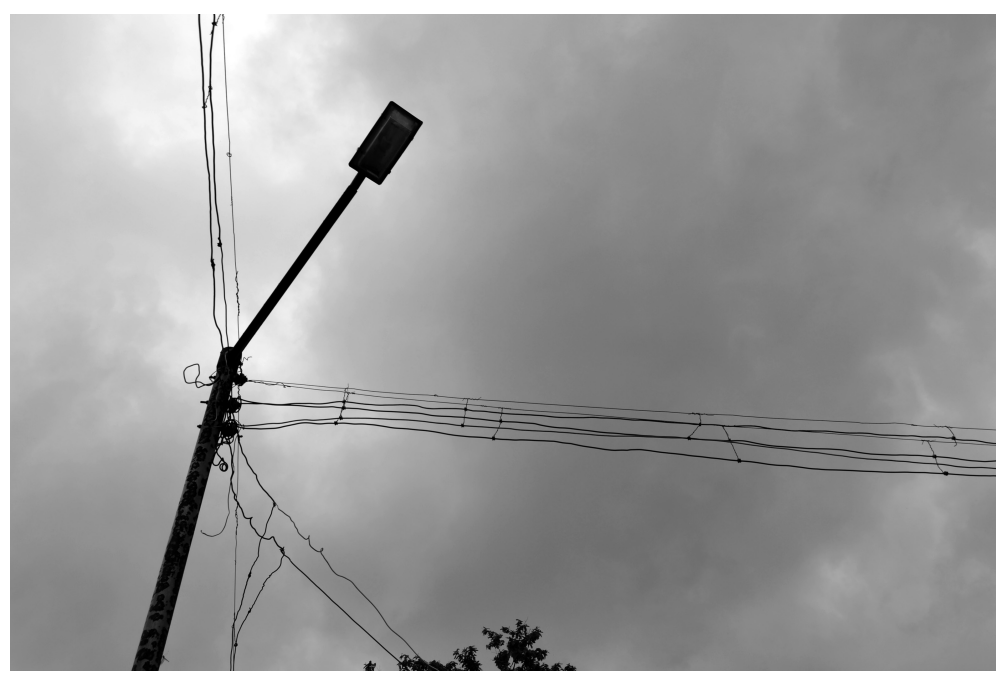

Figure 3.4 Power Distribution Network (PDN) with extra cables connected by the villagers.

music systems and lights (see Figure 3.4). Such contexts foreground the need for reconfiguring the local distribution of electrical energy to power various devices, other than the CFL bulbs installed by CREDA.

The ethnographer observed many intriguing practices to reconfigure the grid in order to address a local problem. For instance, many houses relocated the CFL bulbs provided by CREDA to hang outside of their houses. The villagers narrated that their village remains under threat from herds of elephants. The villagers disclosed that as part of their cultural tradition, they store mahuwa (madhuca longifolia) flowers in their households. The flower is edible and has medicinal value. The villagers said that the wild elephants of the region also eat the flower and can smell the "stored" flowers from a distance. Sometimes a herd of elephants, following the smell of the flower, come searching for it during the night. In their quest, elephants destroy the mud-built houses of the villagers. The villagers explain that the light emitted by a CFL bulb combined with a wind-induced movement of the bulb is sufficient to keep the elephants at bay. This practice of reconfiguring components of the grid enables the villagers to address a local problem through the decentralised grid.

An intriguing aspect of these practices is their shared and socio-communal nature. The villagers elaborated that often any performance of these practices of improvisation, redistribution and adaptation are preceded by deliberations involving the energy committee and the villagers. The grid operator often performs the accompanying "technical" tasks with active participation from other villagers. The role of an energy committee is central for developing a consensus amongst the villagers towards any short-term or enduring improvisations and alterations of 
the grid. CREDA officials clarified that a local energy committee is empowered to develop their own rules for the functioning of the local grid. Further, a committee can determine and execute sanctions against any villager or household in cases of violation of their rules. A benefit of these social and communal practices is a developing sense of ownership amongst the energy committee towards the local grid. CREDA officials state that in the villages where there is a more robust engagement of the local committee with the grid, they also observe better care and protection of the components of the grid. Overall, the existence and performance of these practices of improvisation and adaptation also indicate the villagers' needs and desires to enhance the possibilities offered by a local grid, an intervention for a sustainable energy transition and to connect it with their social, cultural and religious values.

\section{Developing local knowledge and know-how}

These practices of improvisation and reconfiguration of the grids require technical know-how about various components of the grid. The villagers report that their familiarity with the grid's functioning develops by observing and discussing it with the "outsiders", such as electricians, who come to inspect or repair any damaged component of the grid. The villagers state how they built their technical knowhow to negotiate with various components of the grid by participating in periodic maintenance tasks by visiting electricians. An exciting and unintended outcome of this developing local knowledge is the emerging ability of the villagers to do a rudimentary repair of a broken-down device or component of the grid. These practices come in handy when a standard replacement of a damaged item is not available, or if professional repair work is either expensive or is getting delayed.

An associated aspect of these practices of adaptation of the grids is a delicate balance that has to be maintained to avoid overuse of a device at a household that could lead to drawing large amounts of energy from the grid. This situation can potentially lead to complaints from and disputes with other villagers. Hence, such practices require sensorial know-how of local electricity production and storage. The ethnographer was surprised by people's delicate understanding of this. Over the years, the villagers seem to have developed a qualitative understanding of local energy capacity.

\section{Beyond monetary values}

The villagers have designed various non-monetary means of sharing the benefits of energy and the grid. For instance, an electrical socket installed by a household is also used by other villagers for charging their mobile phones. Similarly, a grid operator installed a television and CD player in a room. Pointing to a couple of cots and chairs placed in the room, he narrated how the set-up works as a movie theatre for the village, where villagers gather for communal viewing. By sharing a privately owned device with others, he can avoid the ire of the villagers who are unable to afford these devices (see Figure 3.5). 

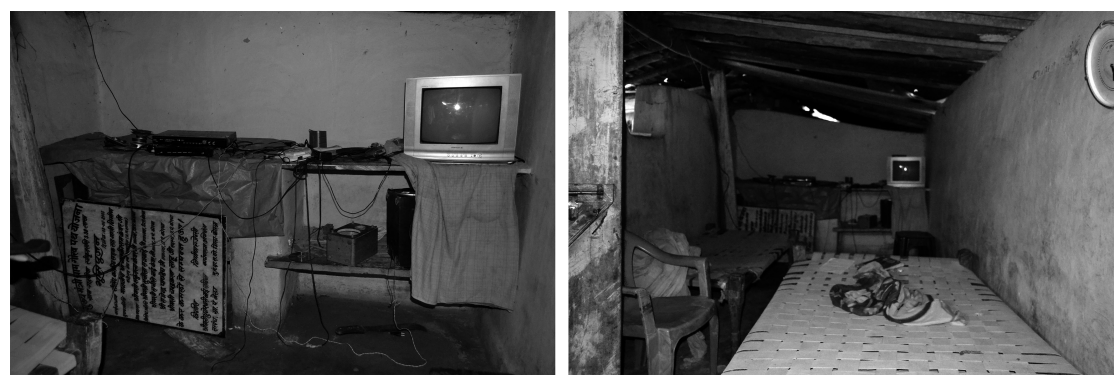

Figure 3.5 A "movie theatre" set-up with a television-set connected to a compact disc (CD) player and with cots and chairs for the villagers to sit.

A discussion on economic benefits and drawbacks of the state-funded decentralised grids falls outside the scope and ambition of this chapter. However, these local practices hint at possibilities of non-market ways for local communities to manage shared production, consumption and exchange of energy through a decentralised grid. CREDA's initial plan was to structure a monetary payment structure, where a grid operator would collect a small monthly fee (INR 5-10) from each household. This collected amount would form a small remuneration for grid operator efforts. CREDA officials reported that payment collection has proved to be a challenging task and they consider it to have been a failure. The payment collection proved difficult due to two main reasons. Firstly, due to economic poverty plaguing these villages, many of the villagers are cash-starved. Most of the villagers do not have any regular employment, and their participation in agricultural activities is primarily for subsistence. Second, grid operators are hesitant to collect monetary payment from their fellow villagers, as this has the potential to strain their local social relations. The values associated with payment collection and market logic seem to be conflicting with the villagers' value of shared and non-monetary means of life in the village.

\section{Local narratives}

CREDA officials, during initial conversations with the ethnographer, had narrated and emphasised various "misuses" and sometimes "abuses" of the mini-grids at the field-sites. They remarked that the villagers often misuse the grid by connecting various power-consuming devices such as radio, television and loudspeaker. They explained that these additional power-consuming devices limit the run-time of the grid and expedite the amount of repair and maintenance. For instance, sometimes the villagers in the process of attaching an extra cable to the PDN damage the existing electrical cables or expose an electrical junction to rainwater and hence introducing safety risks. Similarly, due to an addition of extra electrical load during a local celebration, the battery-bank gets wholly drained in just a few hours. Overall, CREDA officials raised various relevant points of concern associated with these local practices. 
However, during the field-visits accompanied by CREDA officials, the ethnographer was surprised by their informal acceptance of these local practices. Contrary to the narrative of "misuse" and "abuse", the informal stance of the officials is one of acceptance and cautious encouragement for these practices. The ethnographer was amazed by CREDA officials' comments to the villagers that they could make use of the grid as they like. The officials encouraged them to discuss with each other local use of the energy provided by the grid. The emphasis was on building consensus amongst the villagers on use of the grid. Contrary to the initial communication with the ethnographer, the officials stated not having any issues with these practices. The officials' main concern was to avoid any local dispute and hence their emphasis on consensus-building.

Later, an official explained that CREDA has reluctantly accepted these practices, firstly, as these are widespread, and they are unable to control them. Secondly, these practices make the villagers engage and care for the grid, making them into a process of protection of equipment. Hence, it is not surprising that at the time of the field-visits, these grids have been continuously functioning for eight to ten years despite their remote locations.

The narrative and process of consensual local use, appropriation and adaptation of the grid is the core of the informal stance of CREDA. Within the dynamics of this emerging narrative, the conceptual boundaries amongst the meanings of (proper) "use", "misuse" and "abuse" get blurred and negotiated. Taking a more considerate viewpoint, CREDA officials later described the damages caused and safety concerns associated with the local practices as due to lack of awareness and know-how that should be addressed rather than curbed. Overall, these multitudes of local practices have informed the informal policy of CREDA through which the local energy committee is empowered and mandated to configure, appropriate and adapt these decentralised grids.

\section{Composing an inclusive view on sustainable transition to decentralised energy}

As mentioned earlier in the chapter, SET is conceptualised as a technology-laden category in the EU directive. Such a framing leads to the weak picture of the energy transition by informing definitions and policies and shaping the debate. The hegemonic conceptualisation of SET expressed in the EU directive is exclusionary and problematic because it holds a "tunnel vision" on how energy transition should occur through the diffusion of technological innovation and overreliance on market mechanisms. Whereas, as the case study indicated, there might be other ways to engage with energy transition through creative low-tech solutions, for instance. In other words, we suggest that there is a possibility to learn from local practices, knowledge, values and narratives in the global South about alternative socio-technical arrangements around decentralised energy. Although present in energy scholarship (Singh 2019; Kumar et al. 2019; Bombaerts et al. 2020), the systematic inclusion of local values, knowledge, narratives and practices is still missing in the global North's vision on SET and particularly in EU policies. 
Policies can strengthen community bonds with minimal interference with traditions, cultures and social relations by taking the community's knowledge, values, practices and narratives as a starting point. For instance, CREDA's (informal) policy aimed to encourage the villagers to develop consensus to use the grid for their collective goals such as religious celebrations.

In the endeavour of constructing an inclusive view of SET, we draw our inspiration from the work of David Edgerton (2007). The author emphasises the importance of inclusion of local practices into a "big picture" of the narrative of global history (Edgerton 2007). Edgerton (2007) proposes the post-contextual approach, where he emphasises the importance of perceiving local narratives as valuable for the just and fair representation of a "big picture". The author claims that "the point of a post-contextual picture is to give us a different account of the national and global historical context, and the place of technology in it, not merely adding technology to accounts" (Edgerton 2007, p. 85). Incorporation of the local narratives into a "big picture" of SET may facilitate the recognition of local practices, values and knowledge. The local narratives comprise diverse social, cultural, religious and economic contexts for adaptation, appropriation and acceptance of SETs, such as the decentralised grids, by the local communities. As was indicated in the case study, the local narratives are used by the villagers to legitimise intended and unintended "use", "abuse" and "misuse" of the grids. On the one hand, the local villagers, including the energy committee, utilise these narratives to develop consensus within the village. These narratives become key components of implicit and explicit negotiation between the villagers at the one end; and CREDA officials, visiting electricians and eventually CREDA's informal policy at the other end.

Furthermore, incorporation of local knowledge is essential for an inclusive vision of SET as the interactions between material agencies and knowledge production in the ways local people transform and adapt the technologies can enrich a "big picture" of SET (Edgerton 2007, p. 92). This was exemplified in the empirical analysis as practices of improvisation that consist of local approaches to redistribution of energy and adaptation of mini-grids to fit with the dynamics of their life and to address their unmet needs for the energy spanning social and cultural contexts. These contexts, such as festivals, celebrations and rituals of marriage and childbirth, are an integral part of their everyday life that justify the need for alteration in the energy distribution. In other words, such local creative adaptation can be oriented towards the particular needs of the community because these lowtechnological solutions can be made compatible with local practices, knowledge, values and narratives.

Indeed, the empirical case from the global South brings attention to various aspects that may be relevant for design experimentation (Singh et al. 2015, 2019) and policy development in the global North. In a way, the case also hints that for the SET, we do not necessarily need to "push" the latest and "high-tech" innovations. A local creative adaptation and consensus-building in communities may provide spaces for improvisation in a decentralised grid. Such processes have the potential to open a twofold opportunity for SET. First, to engage a local 
community in care, protection and repair through acquired ownership of a decentralised grid. Second, to create localised opportunities to manage shared production, consumption, and exchange of energy. Moreover, it is possible to support local communities by strengthening community bonds and contributing to the wellbeing of locals through creative approaches to energy, localised problemsolving and new forms of ownership. As shown in the example of villagers using lights to keep elephants at bay, local adaptation of the grid has contributed to general wellbeing by preventing damage to health and property.

All in all, the case provides a glimpse of alternative configurations of social life with decentralised energy. While in energy scholarship local empowerment, civic engagement and community ownership are often regarded as a positive side of community energy projects (Koirala et al. 2016; Rogers et al. 2008; Hoppe et al. 2015), in the EU directive such aspects were mostly missing. In our conclusion, we suggest that a vision of SET, where people are not pushed to accept market designs and high-tech innovations, can incorporate local values, knowledge, practices and narratives. Such a vision can open up a space for the emergence of nonmarket structures and non-monetary mechanisms for local engagement in energy decentralisation (Singh et al. 2017, 2018). However, this requires further crosscultural research into a "big picture" of SET through recognising and integrating visions from both the global North and the global South.

\section{Conclusion}

Drawing inspiration from historians of science and technology and utilising empirical findings from an ethnographic field-study on decentralised grids in rural India, in this chapter we have argued that hegemonic conceptualisation of SET does not sufficiently take into account the local narratives, practices, knowledge and values. We first examined the visions on SET implemented in the EU directive and revealed implicit bias about heavy reliance on technological innovation, market design and rational values supporting economic growth. Our empirically informed theoretical approach includes a focus on local practices, narratives, knowledge and a diverse set of values in energy decentralisation discourse on the one hand and the mundane technologies and the practices of improvisation on the other hand. Inspired by the post-contextual approach, this chapter contributes towards a long process of integration of the perspectives from the global South and the global North in the one "big picture" of the SET.

\section{Acknowledgement}

Both the authors, Anna Melnyk and Abhigyan Singh, have contributed equally to this chapter and hence are joint first authors. Abhigyan Singh conducted the reported field-research on solar mini-grids in India as part of his doctoral research. Abhigyan's doctoral research is part of the research programme of University Campus Fryslân (UCF), which is financed by the province of Fryslân in the Netherlands. Anna Melnyk's work on this paper was supported 
by the ValuesChange project that received funding from the European Research Council (ERC) under the European Union's Horizon 2020 research and innovation programme under grant agreement No 788321. The opinions expressed in this document reflect only the authors' views and in no way reflect the European Commission's opinions. The European Commission is not responsible for any use that may be made of the information this document contains. We express our gratitude to the villagers at the field-sites for welcoming Abhigyan and participating in this research. We sincerely thank Chhattisgarh State Renewable Energy Development Agency (CREDA) and its officials for sharing their perspectives, providing relevant background information and enabling the field-visits. Also, we are grateful for all the extensive commenting and feedback done by Johanna Höffken, Ankit Kumar and Auke Pols that helped to improve this chapter.

\section{Note}

1 Authors are co-first authors and have contributed equally to the chapter.

\section{References}

Aitzhan, N. Z., \& Svetinovic, D. (2016). Security and privacy in decentralized energy trading through multi-signatures, blockchain and anonymous messaging streams. IEEE Transactions on Dependable and Secure Computing, 15(5), 840-852.

Becker, S., \& Kunze, C. (2014). Transcending community energy: collective and politically motivated projects in renewable energy (CPE) across Europe. People, Place and Policy Online, 8(3), 180-191. doi: 10.3351/ppp.0008.0003.0004

Bellekom, S., Arentsen, M., \& Gorkum, K.V. (2016). Prosumption and the distribution and supply of electricity. Energy, Sustainability and Society, 6(1). doi:10.1186/ s13705-016-0087-7

Bombaerts, G., Jenkins, K.E., Sanusi, Y.A., \& Guoyu, W. (2020). Energy Justice Across Borders. Cham, Switzerland: Springer Open.

Camarinha-Matos, L.M. (2016). Collaborative smart grids - a survey on trends. Renewable and Sustainable Energy Reviews, 65, 283-294. doi:10.1016/j.rser.2016.06.093

Coenen, L., Benneworth, P., \& Truffer, B. (2012). Toward a spatial perspective on sustainability transitions. Research Policy, 41(6), 968-979.

Cuppen, E., Pesch, U., Remmerswaal, S., \& Taanman, M. (2019). Normative diversity, conflict and transition: Shale gas in the Netherlands. Technological Forecasting and Social Change, 145, 165-175.

Edgerton, D. (2007). Creole technologies and global histories: rethinking how things travel in space and time. Journal of History of Science and Technology, 1, 75-112.

Friedman, B.M. (2006). The moral consequences of economic growth. Society, 43(2), 15-22.

Heldeweg, M. A. (2017). Normative alignment, institutional resilience and shifts in legal governance of the energy transition. Sustainability, 9(7), 1273.

Hoppe, T., Graf, A., Warbroek, B., Lammers, I., \& Lepping, I. (2015). Local governments supporting local energy initiatives: lessons from the best practices of Saerbeck (Germany) and Lochem (The Netherlands). Sustainability, 7(2), 1900-1931. doi: 10.3390/su7021900

Ilic, D., Silva, P.G., Karnouskos, S., \& Griesemer, M. (2012). An energy market for trading electricity in smart grid neighbourhoods. 2012 6th IEEE International Conference on Digital Ecosystems and Technologies (DEST). doi:10.1109/dest.2012.6227918 
Koirala, B.P., Koliou, E., Friege, J., Hakvoort, R.A., \& Herder, P.M. (2016). Energetic communities for community energy: a review of key issues and trends shaping integrated community energy systems. Renewable and Sustainable Energy Reviews, 56, 722-744. doi: 10.1016/j.rser.2015.11.080

Koistinen, K., Teerikangas, S., Mikkilä, M., \& Linnanen, L. (2018). Agent-based change in facilitating sustainability transitions: a literature review and a call for action. Handbook of Engaged Sustainability, 2-2, 1135-1156. doi:10.1007/978-3-319-71312-0_31

Kern, F., \& Smith, A. (2008). Restructuring energy systems for sustainability? energy transition policy in the Netherlands. Energy Policy, 36(11), 4093-4103. doi: 10.1016/j. enpol.2008.06.018

King, L.C., \& Van Den Bergh, J.C. (2018). Implications of net energy-return-on-investment for a low-carbon energy transition. Nature Energy, 3(4), 334-340. doi:10.1038/ s41560-018-0116-1

Kumar, A., Ferdous, R., Luque-Ayala, A., Mcewan, C., Power, M., Turner, B., \& Bulkeley, H. (2019). Solar energy for all? Understanding the successes and shortfalls through a critical comparative assessment of Bangladesh, Brazil, India, Mozambique, Sri Lanka and South Africa. Energy Research \& Social Science, 48, 166-176. doi:10.1016/j. erss.2018.10.005

Kuzemko, C., Mitchell, C., Lockwood, M., \& Hoggett, R. (2017). Policies, politics and demand side innovations: the untold story of Germany's energy transition. Energy Research \& Social Science, 28, 58-67. doi:10.1016/j.erss.2017.03.013

Magnusson, D., \& Palm, J. (2019). Come together-the development of Swedish energy communities. Sustainability, 11(4), 1056. doi: 10.3390/su11041056

Mok, L., \& Hyysalo, S. (2018). Designing for energy transition through value sensitive design. Design Studies, 54, 162-183. doi: 10.1016/j.destud.2017.09.006

Parag, Y., \& Sovacool, B.K. (2016). Electricity market design for the prosumer era. Nature Energy, 1(4). doi:10.1038/nenergy.2016.32

Rae, C., \& Bradley, F. (2012). Energy autonomy in sustainable communities - a review of key issues. Renewable and Sustainable Energy Reviews, 16(9), 6497-6506. doi: 10.1016/j.rser.2012.08.002

Rogers, J., Simmons, E., Convery, I., \& Weatherall, A. (2008). Public perceptions of opportunities for community-based renewable energy projects. Energy Policy, 36(11), 4217-4226. doi: 10.1016/j.enpol.2008.07.028

Saad, W., Glass, A.L., Mandayam, N.B., \& Poor, H.V. (2016). Toward a consumer-centric grid: a behavioral perspective. Proceedings of the IEEE, 104(4), 865-882. doi:10.1109/ jproc.2016.2520760

Singer, P. (2002). One World: The Ethics of Globalization. New Haven: Yale University Press.

Singh, A. (2019). Conceptualizing inter-household energy exchanges: an anthropologythrough-design approach (Doctoral dissertation, Delft University of Technology). doi:10.4233/uuid:57be7165-2726-4a1a-b076-c5ed3988e00b

Singh, A., Strating, A.T., Herrera, N.R., Mahato, D., Keyson, D. \& van Dijk, H.W. (2018). Exploring peer-to- peer returns in off-grid renewable energy systems in rural India: an anthropological perspective on local energy sharing and trading. Energy Research \& Social Science 46, 194-213. doi:https://doi.org/10.1016/j.erss.2018.07.021

Singh, A., Strating, A.T., Romero Herrera, N., van Dijk, H.W., \& Keyson, D. (2017). Towards an ethnography of electrification in rural India: social relations and values in household energy. Energy Research \& Social Science 30, 103-115. doi:https://doi.org /10.1016/j.erss.2017.06.031 


\section{Anna Melnyk and Abhigyan Singh}

Singh, A., van Dijk, H.W., Romero Herrera, N.A., \& Keyson, D.V. (2015). Enabling "new" practices of renewable energy sharing: a cross-cultural approach. Design for Sharing workshop at ACM CHI'15 Conference. Seoul, Republic of Korea. Available at: http://resolver.tudelft.nl/uuid:ef0d858f-499b-4f12-a608-532ca2c4f9b1.

Smith, A., Voß, J.-P., \& Grin, J. (2010). Innovation studies and sustainability transitions: the allure of the multi-level perspective and its challenges. Research Policy, 39(4), 435-448. doi: 10.1016/j.respol.2010.01.023

Spangenberg, J.H. (2004). Reconciling sustainability and growth: criteria, indicators, policies. Sustainable Development, 12(2), 74-86. doi:10.1002/sd.229

Taebi, B., \& Kloosterman, J.L. (2015). Design for values in nuclear technology. In I. Poel, J. Hoven, \& P.E. Vermaas (Eds.), Handbook of Ethics, Values, and Technological Design (pp. 799-823). Dordrecht: Springer.

Union, E. (2018). Directive (EU) 2018/2001 of the European Parliament and of the Council of 11 December 2018 on the promotion of the use of energy from renewable sources. Official Journal of the European Union, 5, 82-209.

Van de Poel, I. (2017). Design for sustainability. In: Kaplan D.M. (Ed.), Philosophy, Technology, and the Environment (pp. 121-142). Cambridge: MIT Press.

Verbong, G., \& Geels, F. (2007). The ongoing energy transition: lessons from a sociotechnical, multi-level analysis of the Dutch electricity system (1960-2004). Energy Policy, 35(2), 1025-1037. doi: 10.1016/j.enpol.2006.02.010

Verkade, N., \& Höffken, J. (2019). Collective energy practices: a practice-based approach to civic energy communities and the energy system. Sustainability, 11(11), 3230. doi: $10.3390 /$ su1 1113230

WCED. (1987). Our Common Future. Brundtland G.H., Angelli S., Al-Athel S., \& Chidzero B. (Eds.). Oxford: World Commission on Environment and Development (WCED).

Wu, J., \& Tran, N.K. (2018). Application of blockchain technology in sustainable energy systems: an overview. Sustainability, 10(9), 3067. 